We accept that facilities for ultrasound cephalometry are not always available and that during pregnancy $x$-ray examination may be undesirable. Furthermore, amniocentesis, which can be uncomfortable for the patient, is dangerous without previous placentography. Fetal hazards, however, may be reduced by the increased, but judicious, use of these tests in patients with an unknown confinement date.

We wish to thank Dr. J. H. Smitham, consultant radiologist, Dr. M. Sandler, consultant chemical pathologist, and Dr. J. PryseDavies, consultant pathologist, for their help with this study.

\section{References}

Beazley, J. M., and Underhill, R. A. (1970). British Medical fournal, 4, 404 Beazley, J. M., and Underhill, R. A. (1971). In Press.

Brosens, I., and Gordon, H. (1966). Fournal of Obstetrics and Gynaecology of the British Commonevealth, 73, 88.

Campbell, S. (1969). Fournal of Obstetrics and Gynaecology of the British Commonrvealth, 76, 603.

Campbell, S., and Newman, G. B. (1971). fournal of Obstetrics and Gynaecology of the British Commonevealth, 78, 513.

Chan, W. H., Willis, J., and Woods, J. (1969). Fournal of Obstetrics and Gynaecology of the British Commonevealth, 76, 193.

Hartley, J. B. (1957). British fournal of Radiology, 30, 561.

Lind, T., Parkin, F. M., and Cheyne, G. A. (1969). Fournal of Obstetrics and Gynaecology of the British Commonwealth, 76, 673.

Park, G. L. (1968). Lancet, 2, 1388.

Russel, j. (1969). Fournal of Obstetrics and Gynaecology of the British Commonwealth, 76, 208 .

\title{
Trimethoprim and Sulphamethoxazole in Typhoid Fever in Children
}

\author{
J. N. SCRAGG， C. J. RUBIDGE
}

British Medical fournal, 1971, 3, 738-741

\section{Summary}

One hundred and three children with proved typhoid fever were treated with trimethoprim-sulphamethoxazole, and the results compared with those of a further $\mathbf{4 0}$ children treated with chloramphenicol. The bacteriological response to trimethoprim-sulphamethoxazole was unsatisfactory. From this study it seems that at present chloramphenicol is still the treatment of choice for typhoid fever. In view of the haematological changes occurring during therapy with trimethoprim-sulphamethoxazole caution is necessary and monitoring of the blood picture advisable, even at the recommended dose.

\section{Introduction}

Our considerable experience in the treatment of typhoid fever with chloramphenicol (Scragg et al., 1969) indicated that a 21-day course of therapy was necessary to keep the relapse rate of this disease at a low level. The manufacturers of the drug combination trimethoprim-sulphamethoxazole claim success in the treatment of salmonella infections, the recommended course being 14 days.

The purpose of this study was to establish if this drug combination achieved the same satisfactory response both clinically and bacteriologically that chloramphenicol has given. If it did, and was also able to shorten the duration of therapy and thereby hasten discharge from hospital, this would be an advance in therapeutic management.

\section{Patients and Methods}

During the study period (September 1969 to April 1971) 240 cases of typhoid were admitted to this unit. There were 12 deaths, nine of them occurring shortly after admission and

Department of Paediatrics and Child Health, University of Natal, Durban, South Africa

J. N. SCRAGG, M.D., D.C.H., Principal Paediatrician/Senior Lecturer C. J. RUBIDGE, M.B., D.C.H., Senior Paediatrician/Senior Lecturer before treatment could be instituted. Of the remaining three the diagnosis was not suspected before death in two; the third child is included in this trial. A further 85 cases were excluded from the series because Salmonella typhi was not isolated from the blood culture. One hundred and forty-four symptomatic cases of typhoid fever, all proved by isolation of Salm. typhi in blood and/or clot culture, are therefore included in this study.

At the start of the study we decided to treat all cases with trimethoprim-sulphamethoxazole. When it was apparent that the response in the first $\mathbf{4 0}$ cases was disappointing we thought it wise to compare the therapeutic response with that to chloramphenicol during this epidemic to confirm our past experience of its efficacy. Thus as the study proceeded typhoid admissions to two wards were given trimethoprim-sulphamethoxazole while those to another two wards were treated with chloramphenicol. All the cases were under our personal care.

One hundred and four patients received the drug on trial and 40 received chloramphenicol (Parke Davis). On admission, in addition to positive blood cultures, 22 had positive stool cultures, nine positive urine cultures, and nine positive cultures for both stool and urine. Most had significantly raised agglutination titres.

After the initial cultures of blood, stool, and urine on admission, blood cultures were repeated during the period of therapy in $114(80 \%)$. Stool and urine samples were cultured after cessation of the drugs until at least three successive negative cultures were obtained for each. Full blood counts were done before therapy in all patients (see Table II). Thereafter they were repeated throughout the period of therapy at least biweekly and more often if indicated. Absolute platelet counts were done in only 50 patients. In a further 59 the platelets were reported as normal or reduced in numbers from the study of the peripheral blood smears. In-vitro sensitivity tests were not possible in all cases. However, this test was done in 68 of the trimethoprim-sulphamethoxazole group. Salm. typhi was tested against the drug combination but not to each separate component.

\section{DOSAGE SCHEDULES}

Trimethoprim-Sulphamethoxazole.-We undertook to administer two "paediatric" tablets 12-hourly for 14 days. Thus, initially, the dose was not based on the weight of the patient. After 
embarking on the trial the manufacturers suggested that the dose should be $4 \mathrm{mg}$ of trimethoprim and $20 \mathrm{mg}$ of sulphamethoxazole per $\mathrm{kg}$ of body weight per day for 14 days. The poor results on analysis of the first 40 cases decided us to extend the course to 21 days in the hope that the relapse and carrier rates might be reduced. Subsequently the manufacturers suggested that the dose should be increased to trimethoprim $6 \mathrm{mg}$ and sulphamethoxazole $30 \mathrm{mg} / \mathrm{kg} /$ day and, still later, to double the original dose (see Table V).

Chloramphenicol.- The group of $\mathbf{4 0}$ children treated with chloramphenicol received $50 \mathrm{mg} / \mathrm{kg} /$ day for 21 days.

Because of the high incidence of folic acid deficiency in malnourished children in this area, all patients received folic acid $15 \mathrm{mg} /$ day in addition to multivitamin syrup.

\section{Clinical Details}

The group of 144 patients comprised 139 African and 5 Indian children. Thirty-five fell in the age group 2-6 years and 109 were aged 7 to 12 years. All but 19 were undernourished on a weight for age basis, 68 of them falling below the 3rd percentile of the Boston Scale. The length of illness before admission to hospital was obtained in all but two cases. This ranged from 2 to 28 days, with a median of 7 days in both treatment groups. On the basis of toxicity, meningismus, delirium, etc., 107 were severely ill, the remaining 27 were moderately ill. One child died within 72 hours of admission.

In the trimethoprim-sulphamethoxazole group two showed evidence of haemolysis on admission, seven had acute nephritis, and two were jaundiced, both with slightly deranged liver function tests. In the chloramphenicol group two had a picture suggestive of hepatitis and one had acute nephritis on admission.

\section{Results}

The clinical response was judged by relief of toxicity, improvement in well-being, and return of appetite. Apart from the one child who died within 72 hours of admission, all but $11(89 \%)$ in the trimethoprim-sulphamethoxazole group showed a striking and rapid response in general well-being within 48 to 72 hours after the start of the drug despite a continuing high fever in many. The clinical response in the chloramphenicol group was much slower in onset and far less striking. Only $22(55 \%)$ showed a satisfactory response within four to five days. The response of temperature in the two groups is shown in Table I. The jaundiced patients and those with acute nephritis in both groups showed no adverse effects from either drug administered.

TABLE I-Temperature Response

\begin{tabular}{|c|c|c|c|}
\hline & \multicolumn{2}{|c|}{ Trimethoprim-Sulphamethoxazole } & \multirow{2}{*}{$\begin{array}{l}\text { Chloramphenicol } \\
40 \times 21 \text { days }\end{array}$} \\
\hline & $\begin{array}{c}\text { All Cases } \\
40 \times 14 \text { days } \\
63 \times 21 \text { days } \\
\end{array}$ & $\begin{array}{l}\text { Double Dose } \\
22 \times 21 \text { days }\end{array}$ & \\
\hline $\begin{array}{cc}\text { Response-no return } \\
\text { of fever } \quad \ldots & \ldots \\
\text { Range (Days) } & \ldots \\
\text { Median (Days) } & \ldots\end{array}$ & $\begin{array}{c}56(54 \%) \\
2-13 \\
7 \\
\text { (9 became carriers) }\end{array}$ & $\begin{array}{c}8(36 \%) \\
4-11 \\
7 \\
\text { (2 became carriers) }\end{array}$ & $\begin{array}{c}24(60 \%) \\
2-12 \\
7 \\
\text { (1 became carrier) }\end{array}$ \\
\hline $\begin{array}{l}\text { Initial response- } \\
\text { return of fever later }\end{array}$ & $\begin{array}{c}31(30 \%) \\
\text { (11 relapsed, } \\
5 \text { became carriers) }\end{array}$ & $\begin{array}{c}10(45 \%) \\
\text { (2 relapsed, } \\
3 \text { became carriers) }\end{array}$ & $\begin{array}{c}10(25 \%) \\
(2 \text { relapsed })\end{array}$ \\
\hline $\begin{array}{l}\text { Lack of response- } \\
\text { fever throughout } \\
\text { course }\end{array}$ & $\begin{array}{c}9(8 \%) \\
(1 \text { death within } \\
72 \text { hours. } 8 \text { positive } \\
\text { blood cultures } \\
\text { following course) }\end{array}$ & $\begin{array}{c}3(14 \%) \\
\text { (All positive blood } \\
\text { cultures following } \\
\text { course) }\end{array}$ & $\begin{array}{c}1(2.5 \%) \\
\text { (Positive blood } \\
\text { culture following } \\
\text { course) }\end{array}$ \\
\hline $\begin{array}{l}\text { Afebrile-low-grade } \\
\text { fever at start of drug }\end{array}$ & $\begin{array}{c}8(8 \%) \\
(2 \text { relapsed) }\end{array}$ & $1(5 \%)$ & $5(12.5 \%)$ \\
\hline
\end{tabular}

\section{HAEMATOLOGICAL STUDY}

Table II indicates the haemoglobin and leucocyte counts on admission and before treatment in the two groups. In both groups, over $40 \%$ showed haemoglobin levels of less than $10 \mathrm{~g} / 100 \mathrm{ml}$. Blood transfusions were given when indicated. With the exception of one patient, discussed below, all, including the two with haemolysis, made a complete recovery. Table III shows the absolute neutrophil counts before and lowest counts during therapy. The time of occurrence of the latter is indicated. Seventy cases in the trimethoprim-sulphamethoxazole group often had repeated and detailed blood studies done. Absolute neutrophil counts during therapy showed that $30(43 \%)$ had fallen below 2,000, 18 of them below 1,500. In 38 of the chloramphenicol group with detailed haematological study, $8(21 \%)$ showed absolute neutrophil counts below 2,000, but only one fell below 1,500 .

TABLE II-Haemoglobin and Leucocyte Counts on Admission in Both Treatment Groups

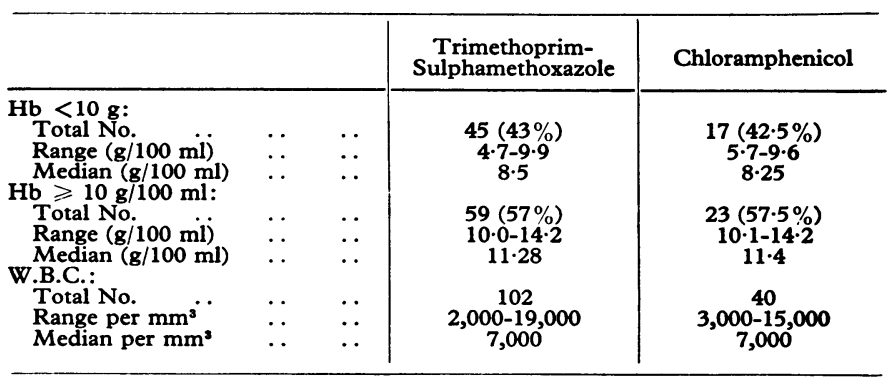

TABLE III-Absolute Neutrophil Counts before and during Therapy in Both Groups

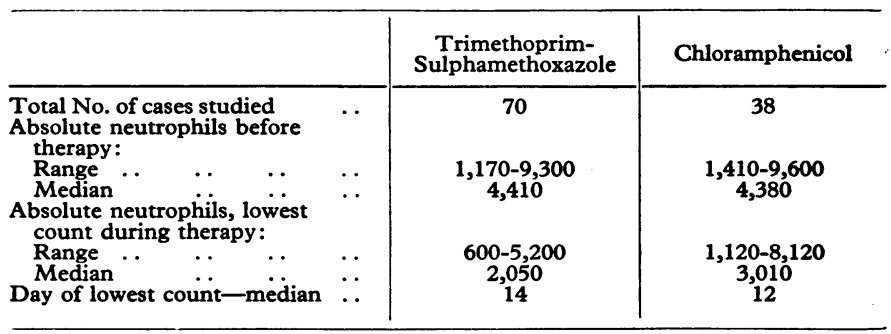

In the trimethoprim-sulphamethoxazole group 78 patients had adequate platelet studies. Fifty-six of these had normal platelets on admission and throughout the period of treatment. A moderate thrombocytopenia was present on admission in $14(18 \%)$. However, during treatment platelets rose to normal levels and remained so after therapy in 10. The other four continued with reduced platelets but returned to normal levels by the end of the period of therapy or shortly thereafter. A further eight with normal platelets on admission showed a temporary reduction during therapy. In all of these the platelet levels became normal towards the end of the treatment period. In the chloramphenicol group 31 had platelet studies. Twentyfour had normal platelets on admission and throughout therapy. A moderate thrombocytopenia was present in 7 (22.5\%). During therapy platelets rose to normal levels in all.

\section{BACTERIOLOGICAL STUDY}

Repeat blood cultures in 114 patients (Table IV) showed that Salm. typhi was recovered in 19 out of 80 patients in the trimethoprim-sulphamethoxazole group at 4 to 19 days after starting therapy. A positive blood culture was obtained from one patient in the chloramphenicol group four days after starting therapy. 
TABLB IV-Repeat Blood Cultures in 114 Patients during Therapy

\begin{tabular}{|c|c|c|c|c|c|c|c|c|c|c|c|c|c|}
\hline \multirow{2}{*}{ Group } & \multirow{2}{*}{$\begin{array}{l}\text { No. of } \\
\text { Cases }\end{array}$} & \multirow{2}{*}{$\begin{array}{c}\text { Total } \\
\text { Positive }\end{array}$} & \multicolumn{11}{|c|}{ Day of Therapy } \\
\hline & & & 4 & 5 & 6 & 7 & 9 & 10 & 12 & 14 & 15 & 16 & 19 \\
\hline $\begin{array}{l}\text { Trimethoprim- } \\
\text { sulphamethorazole } \\
\text { Chloramphenicol }\end{array}$ & $\begin{array}{l}80 \\
34\end{array}$ & $\begin{array}{r}19 \\
1\end{array}$ & $\begin{array}{l}2 \\
1\end{array}$ & 3 & 2 & 2 & $\begin{array}{l}3 \\
-\end{array}$ & 2 & 1 & 1 & 1 & 1 & 1 \\
\hline
\end{tabular}

\section{ADVERSE REACTIONS}

The following cases in the trimethoprim-sulphamethoxazole group showed adverse reactions.

A 12-year-old boy receiving trimethoprim $6.9 \mathrm{mg}$ and sulphamethoxazole $34.5 \mathrm{mg} / \mathrm{kg} /$ day developed a pronounced neutropenia (absolute count 640 ) after 19 days of therapy, which was then

TABLE v-Duration of Therapy, Size of Dose, and Bacteriological Response in the Two Groups

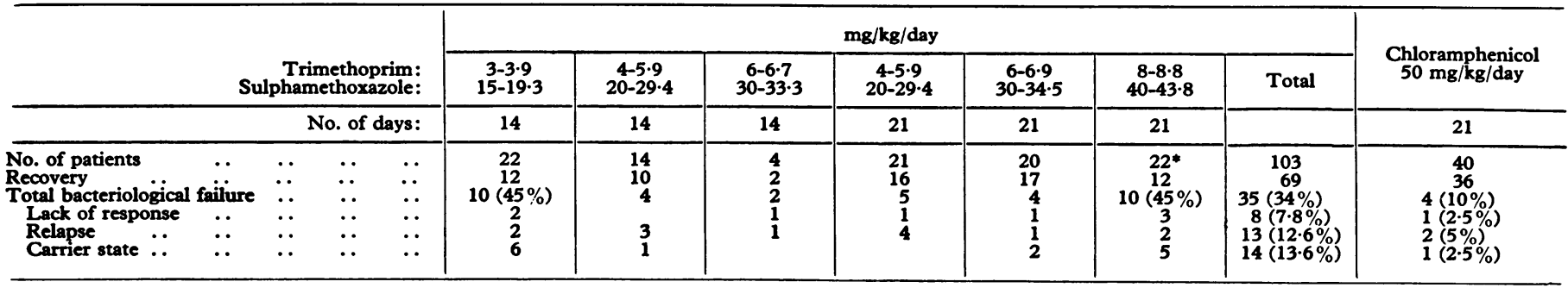

-One death within 72 hours excluded.

Bacteriological follow-up after therapy is shown in Table V. Lack of Response.-This was considered to have occurred if patients remained ill and febrile throughout and Salm. typhi was recultured from the blood after cessation of the drug. The lack of response was $7 \cdot 8 \%$ and $2.5 \%$ in the two groups respectively.

Relapse.-The evidence for this diagnosis was a recurrence of symptoms after initial response and reisolation of the Salm. typhi from the blood. This occurred in $12.6 \%$ of the trimethoprim-sulphamethoxazole group and 5\% of the chloramphenicol group.

Carrier State.-This was based on reisolation of the Salm. typhi from the stool and/or urine from patients who were apparently well and afebrile. The carrier rate was $13.6 \%$ and $2.5 \%$ respectively.

The lack of response, relapse, and carrier rates could not be correlated with the severity or duration of illness before treatment in either group (Table VI).

TABLE vI-Duration of History Related to Lack of Response, Relapse, Carrier Rate

\begin{tabular}{|c|c|c|c|c|c|c|}
\hline \multirow{2}{*}{\multicolumn{2}{|c|}{ Duration of illness before }} & \multirow[b]{2}{*}{.. } & \multicolumn{2}{|c|}{$\begin{array}{l}\text { Trimethoprim- } \\
\text { Sulphamethoxazole }\end{array}$} & \multicolumn{2}{|c|}{ Chloramphenicol } \\
\hline & & & $\leqslant 7$ days & $\geqslant 8$ days & $\leqslant 7$ days & $\geqslant 8$ day: \\
\hline $\begin{array}{l}\text { Lack of response } \\
\text { Relapse .. } \\
\text { Carrier state }\end{array}$ & $\ddot{0}$ & $\ddot{x}$ & $\begin{array}{l}4 \\
6 \\
7\end{array}$ & $\begin{array}{l}4 \\
7 \\
7\end{array}$ & $\begin{array}{l}1 \\
2 \\
1\end{array}$ & $\overline{-}$ \\
\hline
\end{tabular}

The Salm. typhi recovered on isolation before treatment from 68 patients were all sensitive to trimethoprim-sulphamethoxazole. Eleven reisolated during the period of therapy showed nine still sensitive, while two from patients who had had five days of the drug had become resistant. These patients recovered satisfactorily without the occurrence of further positive cultures. Nineteen late isolations after therapy showed that the organisms were still sensitive in all but one patient who had relapsed. This group comprised three in whom there was lack of response throughout, 10 relapses, and six carriers.

Trimethoprim-sulphamethoxazole was readily acceptable to all of the children. One infant, excluded from the series because of lack of positive blood culture, developed pronounced anorexia and vomiting while on the drug. It was necessary to stop therapy after 14 days. These symptoms disappeared within 48 hours of stopping the drug. None of the patients on chloramphenicol showed intolerance. terminated. His blood picture returned to normal over the following three weeks. An 8-year-old girl on the eighth day of therapy (trimethoprim $4 \mathrm{mg}$ and sulphamethoxazole $20 \mathrm{mg} / \mathrm{kg} /$ day) had an absolute neutrophil count of 698 . Therapy was stopped. There was a prompt reticulocytosis but neutropenia persisted for a further three weeks, followed by a gradual return to a normal blood picture one month later. After 15 days of therapy (trimethoprim 8.5 mg and sulphamethoxazole $42.8 \mathrm{mg} / \mathrm{kg} /$ day) in a third child aged 4 years the absolute neutrophil count was 600 . Daily blood examination thereafter showed the neutrophils rising steadily with a satisfactory reticulocyte response and return to normal three weeks later. None of these patients had evidence to suggest hepatic or renal disease.

A child aged 5 years had a normocytic/normochromic anaemia with haemoglobin $6.7 \mathrm{~g} / 100 \mathrm{ml}$ on admission. Unfortunately the initial blood specimen was unsuitable for white cell estimation. On the ninth day of therapy (trimethoprim $5 \mathrm{mg}$ and sulphamethoxazole $25 \mathrm{mg} / \mathrm{kg} /$ day) pronounced pallor was noted. Repeat blood count showed a haemoglobin of $3.0 \mathrm{~g} / 100 \mathrm{ml}$ and white cells $4,000 / \mathrm{mm}^{3}$. Therapy was stopped. The haemoglobin, raised to $8.2 \mathrm{~g} / 100 \mathrm{ml}$ by transfusion, again fell rapidly to $3.9 \mathrm{~g} / 100 \mathrm{ml}$ and white cells to $2,000 / \mathrm{mm}^{3}$ (absolute neutrophils 460 ). Marrow biopsy showed a hypocellular picture with scanty red cell precursors. Despite prednisone and testosterone therapy and frequent blood transfusions the blood and marrow picture remained one of hypoplasia. Death occurred eight months after admission. Necropsy revealed that death was due to a massive haemorrhage into the gastrointestinal tract. Apart from bronchopneumonia there was no underlying disease and no evidence of leukaemia. Bone marrow studies were again consistent with hypoplastic anaemia.

No adverse reactions occurred in the chloramphenicol group and it was not necessary to stop therapy in any of the patients.

\section{Discussion}

The rapid improvement in well-being despite a continuing high fever was most striking in the patients receiving trimethoprim-sulphamethoxazole. The clinical response and disappearance of toxaemia appeared sooner and was much more pronounced than in the chloramphenicol group. This has also been the experience of Kamat (1970). The response of fever to the drug combination was unexpectedly disappointing. Akinkugbe et al. (1968), in a series of 10 cases, and Farid et al. (1970), who studied eight proved cases of typhoid fever, had reported a most satisfactory response. Nevertheless, in our study of 144 children there was no striking difference between the two drug groups with regard to temperature response (Table I).

From studies done elsewhere trimethoprim-sulphamethoxa- 
zole has given as good if not better results than chloramphenicol (Akinkugbe et al., 1968; Kamat, 1970). Thus it was surprising that repeat blood cultures in 80 of the cases during the period of therapy showed several positive isolations in the second and even the third week of treatment with trimethoprimsulphamethoxazole (Table IV). This has not been our experience in many chloramphenicol-treated cases in the past, and occurred in only one in the present series.

We have shown that in the treatment of typhoid trimethoprimsulphamethoxazole is significantly inferior $(P<0.02)$ compared with chloramphenicol. The size of dose or duration of therapy does not seem to account for the disappointing results, as with the smallest dose for 14 days and the largest dose for 21 days the bacteriological failure rate was the same (45\%).

The carrier rate for the trimethoprim-sulphamethoxazole group is unduly high $(13.6 \%)$. Our previous studies of children treated with 21 days of chloramphenicol did not include long-term follow-up stool and urine cultures. In this present chloramphenicol series only one $(2.5 \%)$ became a carrier. There are no published reports of long-term follow-up in typhoid patients treated with trimethoprim-sulphamethoxazole. In a series of 50 cases reported from Rhodesia (Wicks and Stamp, 1970) one became a carrier. In view of our findings long-term follow-up would appear to be indicated.

Testing the sensitivity to trimethoprim-sulphamethoxazole was apparently no guide to response, for with the exception of three cases the Salm. typhi were all sensitive. In two of these three the outcome was not influenced by the early appearance of resistance, while in the third the resistance may have accounted for the relapse. Testing the sensitivity of Salm. typhi to each separate component of this drug may be of more value.

Reports have already appeared on the toxic effects on the bone marrow after the use of trimethoprim-sulphamethoxazole (Evans and Tell, 1969; Mohan, 1969; Paulley, 1970). There can be no certainty about the aetiology of the hypoplastic anaemia in the one patient in this series. This may or may not have been related to trimethoprim-sulphamethoxazole. However, pronounced neutropenia occurred in others and in three instances (excluding the case of hypoplastic anaemia) gave rise to alarm. While most patients on chloramphenicol showed some reduction in neutrophils the effect was less pronounced.

In an earlier study on typhoid in children (Scragg et al., 1969) $23 \%$ of patients showed a moderate thrombocytopenia on admission before treatment. For this reason we do not feel that thrombocytopenia is a helpful guide to detecting drug toxicity. In the present trial the presence of thrombocytopenia on admission was about the same in the two groups $(18 \%$ and $22.5 \%$ respectively). With the one exception of the patient with marrow hypoplasia all the patients in both groups showed a return to normal platelet levels either during or very shortly after therapy, which is probably a reflection of recovery from typhoid toxicity.
The dangers of bone marrow depression from chloramphenicol are well recognized and documented. Like Huckstep (1962) we feel that the dangers of chloramphenicol, while real, have been much overrated. After many years of its use in typhoid and meningitis in children we personally have not encountered a case of hypoplastic or aplastic anaemia resulting from its use, nor has it been necessary to stop therapy because of bone marrow depression. Our findings in this study serve as a warning that, as with chloramphenicol, it is necessary to monitor the blood picture when administering trimethoprim-sulphamethoxazole even at the recommended level of dosage.

One of the original purposes of this study was to establish whether this drug combination gave the same satisfactory response that chloramphenicol has given. We have established that trimethoprim-sulphamethoxazole was inferior to chloramphenicol from the bacteriological point of view. Another object was to establish whether the 14 days' therapy recommended would mean a shortened hospital stay. Far from cutting down the hospital stay the "failures" greatly increased the length of stay in hospital, as further courses of therapy and follow-up stool and urine cultures were required.

Possibly in Durban at present the strain of organism is different from that causing typhoid in areas from which the published data on the use of this drug appear.

It is our impression, and that of others, that the response to chloramphenicol is not as satisfactory as formerly. Nevertheless, none of the drugs that have been evaluated against chloramphenicol have been found to be therapeutically superior. Though we would welcome an alternative drug for the treatment of typhoid, at present, in our opinion, chloramphenicol is still the drug of choice.

We wish to thank Dr. H. R. J. Wannenburg, medical superintendent, King Edward VIII Hospital, Durban, for facilities; Professor E. B. Adams for the bone marrow studies; Miss J. G. Krogh, department of microbiology, University of Natal, for the sensitivity tests; and Messrs. Roche Products (Pty.) Limited for the generous supply of trimethoprim-sulphamethoxazole.

\section{References}

Akinkugbe, O. O., Lewis, E. A., Montefiore, D., and Okubadejo, O. A. (1968). British Medical Fournal, 3, 721.

Evans, D. I. K., and Tell, R. (1969). British Medical fournal, 1, 578.

Farid, Z., et al. (1970). British Medical fournal, 3, 323.

Huckstep, R. L. (1962). Typhoid Fever and Other Salmonella Infections. Edinburgh, Livingstone.

Kamat, S. A. (1970). British Medical fournal, 3, 320.

Kamat, S. A. (1970). British Medical four

Paulley, J. W. (1970). British Medical fournal, 2, 364

Scragg, J., Rubidge, C., and Wallace, H. L. (1969). Archives of Disease in

Wicks, A. C. B., and Stamp, T. J. (1970). British Medical fournal, 4, 52. 